NOTES AND CORRESPONDENCE

\title{
Improving Snowfall Forecasting by Accounting for the Climatological Variability of Snow Density
}

\author{
ERIC C. WARE \\ Department of Earth and Atmospheric Sciences, Cornell University, Ithaca, New York
}

DAVID M. SChUltz

Cooperative Institute for Mesoscale Meteorological Studies, University of Oklahoma, and NOAA/National Severe Storms Laboratory, Norman, Oklahoma

HAROLD E. BROOKS

NOAA/National Severe Storms Laboratory, Norman, Oklahoma

Paul J. Roebber and Sara L. Bruening

Atmospheric Science Group, Department of Mathematical Sciences, University of Wisconsin-Milwaukee, Milwaukee, Wisconsin

(Manuscript received 30 August 2004, in final form 26 May 2005)

\begin{abstract}
Accurately forecasting snowfall is a challenge. In particular, one poorly understood component of snowfall forecasting is determining the snow ratio. The snow ratio is the ratio of snowfall to liquid equivalent and is inversely proportional to the snow density. In a previous paper, an artificial neural network was developed to predict snow ratios probabilistically in three classes: heavy $(1: 1<$ ratio $<9: 1)$, average $(9: 1 \leq$ ratio $\leq 15: 1$ ), and light (ratio $>15: 1$ ). A Web-based application for the probabilistic prediction of snow ratio in these three classes based on operational forecast model soundings and the neural network is now available. The goal of this paper is to explore the statistical characteristics of the snow ratio to determine how temperature, liquid equivalent, and wind speed can be used to provide additional guidance (quantitative, wherever possible) for forecasting snowfall, especially for extreme values of snow ratio. Snow ratio tends to increase as the low-level (surface to roughly $850 \mathrm{mb}$ ) temperature decreases. For example, mean low-level temperatures greater than $-2.7^{\circ} \mathrm{C}$ rarely (less than $5 \%$ of the time) produce snow ratios greater than $25: 1$, whereas mean low-level temperatures less than $-10.1^{\circ} \mathrm{C}$ rarely produce snow ratios less than $10: 1$. Snow ratio tends to increase strongly as the liquid equivalent decreases, leading to a nomogram for probabilistic forecasting snowfall, given a forecasted value of liquid equivalent. For example, liquid equivalent amounts $2.8-4.1 \mathrm{~mm}(0.11-0.16 \mathrm{in}$.) rarely produce snow ratios less than 14:1, and liquid equivalent amounts greater than $11.2 \mathrm{~mm}$ (0.44 in.) rarely produce snow ratios greater than 26:1. The surface wind speed plays a minor role by decreasing snow ratio with increasing wind speed. Although previous research has shown simple relationships to determine the snow ratio are difficult to obtain, this note helps to clarify some situations where such relationships are possible.
\end{abstract}

\section{Introduction}

Forecasting the accumulation of new snow is arguably the most challenging quantitative precipitation forecasting problem. Forecasters must not only cor-

Corresponding author address: Dr. David M. Schultz, NOAA/ National Severe Storms Laboratory, 1313 Halley Circle, Norman, OK 73069.

E-mail: david.schultz@noaa.gov rectly predict the occurrence, timing, and location of precipitation, but they are also expected to predict the accumulation of the snow. To accomplish this task, forecasters rely heavily on numerical weather prediction models for guidance. Such models do not output snowfall explicitly, so forecasters must convert the liquid precipitation output by the models to solid precipitation manually. As reviewed in Roebber et al. (2003), this conversion is usually performed using a constant ratio of snowfall to liquid equivalent (hereafter called 
the snow ratio). This ratio, which is inversely proportional to the snow density, is typically assumed to be about 10:1 (10 in. of snow equal $1 \mathrm{in}$. of liquid water; 1 in. $=25.4 \mathrm{~mm})$. In contrast, observations of the snow ratio from large and disparate datasets can range from values near 3:1 to those approaching 100:1 (Currie 1947; LaChapelle 1962, reproduced in Doesken and Judson 1997, p. 15; Power et al. 1964; Super and Holroyd 1997; Judson and Doesken 2000; Roebber et al. 2003; Baxter et al. 2005). Therefore, substantial improvement in forecasting snowfall may be possible by improving techniques to forecast snow ratio.

Roebber et al. (2003) reviewed previous attempts to forecast snow ratio and have shown that they have not been successful because the exact processes affecting snowfall density are not simple or well understood. To attempt some progress, Roebber et al. (2003) developed an ensemble of artificial neural networks for forecasting snow ratio. The ensemble of artificial neural networks provided probabilistic forecasts of the likelihood of the snow ratio being average (9-15:1), above average $(>15: 1)$, or below average $(<9: 1)$. This approach showed substantial improvement over climatology and other methods currently applied by operational forecasters.

A Web-based forecast application of the Roebber et al. (2003) neural network technique has now been implemented online (information at http://sanders. math.uwm.edu/cgi-bin-snowratio/sr_intro.pl). This Web site allows a user to select a forecast model sounding from numerous sites across North America and apply the neural network ensemble approach of Roebber et al. (2003) to determine the probability of snow ratio within each of the three classes, given that snow occurs.

The purpose of this note is to provide some insight into the statistical properties of the Roebber et al. (2003) dataset. Our hope is to provide some additional guidance that could be applied by operational forecasters for forecasting snowfall, such as climatological characteristics not specifically accounted for by the neural networks (e.g., local microclimatological effects that may vary across stations).

Because of the complexity of relationships between temperature, moisture, compaction, and wind that affect snow density, discussed by Roebber et al. (2003), simple relationships are unlikely. At the very least, however, we hope to determine the conditions for which extreme snow ratios are likely or not likely to occur, such that forecast busts due to an incorrect application of a central value of snow ratio (such as 10:1) can be avoided. This approach suggests that the human forecaster can, and should, still play an important role in the forecast process for winter precipitation.

In section 2, we discuss the dataset-the same one developed and applied by Roebber et al. (2003). In section 3, we present the geographical variation of snow-ratio distributions at 28 stations. Sections 4-6 discuss the dependence of snow ratio on the temperature, liquid equivalent, and wind speed, respectively. Finally, section 7 concludes this paper with guidelines for forecasting snow ratio.

\section{Data}

The dataset for this study consisted of 1650 snowfall events between 1973 and 1994 from 28 stations around the United States. The data were compiled and quality controlled as described more fully by Roebber et al. (2003). A brief review follows.

The 6-h new-snow amounts come from the United States Air Force DATSAV2 Surface Climatic database, whereas the National Climatic Data Center (NCDC) hourly precipitation dataset TD-3240 provided the liquid equivalent precipitation corresponding to each snow event. Two different datasets were required because the DATSAV2 dataset generally included only 24-h precipitation amount and the hourly precipitation dataset did not include new-snow amounts. Two 6-h snowfall amounts on either side of 0000 or 1200 UTC are summed to produce a 12-h snowfall amount that is compared to the 12-h precipitation amount summed from the hourly precipitation dataset. To limit potential errors in the calculation of the snow ratio, the accumulation of 12-h new snow must have measured at least $50.8 \mathrm{~mm}(2 \mathrm{in}$.) and the $12-\mathrm{h}$ melted equivalent precipitation at least $2.8 \mathrm{~mm}$ (0.11 in.). Excluding snowfall events with the above criteria and where other precipitation types fell during the 12-h period (e.g., rain, freezing rain, sleet), $22.7 \%$ of the total available snowfall was included in this dataset. Percentages for each station are listed in Table 1.

One of the principal challenges in using snowfall data are potential biases in the measurement of liquid equivalent precipitation from the type of gauge, its location, its exposure, and the type of wind shield, if any (e.g., Groisman and Easterling 1994; Doesken and Judson 1997; Yang et al. 1998). When the wind speed is 6-7 $\mathrm{m} \mathrm{s}^{-1}$, the precipitation gauge used by the National Weather Service has an undercatch of as much as $70 \%$ compared to measuring liquid equivalent from snow cored off a sheltered snowboard (e.g., Goodison 1978; Yang et al. 1998). Consequently, the results of this study should be viewed as representing the snow amount that is measured in the gauge rather than the 
TABLE 1. Statistical properties of snow ratio by station. Std devs with asterisks indicate cities with fewer than 30 events. These data have not been corrected for wind speed or other gauge biases.

\begin{tabular}{|c|c|c|c|c|c|}
\hline Station & No. of events & $\begin{array}{c}\text { Percent of total } \\
\text { snowfall }\end{array}$ & Mean & Median & Std dev \\
\hline Albany, NY & 104 & 38.9 & 13.3 & 12.1 & 7.1 \\
\hline Amarillo, TX & 22 & 21.3 & 13.3 & 13.4 & $5.1^{*}$ \\
\hline Bismarck, ND & 44 & 18.0 & 18.4 & 16.2 & 8.6 \\
\hline Buffalo, NY & 106 & 19.5 & 15.9 & 14.8 & 7.4 \\
\hline Caribou, ME & 123 & 23.3 & 14.3 & 12.9 & 6.6 \\
\hline Dayton, OH & 29 & 18.0 & 14.6 & 12.4 & $7.1 *$ \\
\hline Denver, $\mathrm{CO}$ & 100 & 29.7 & 16.0 & 14.4 & 7.5 \\
\hline Dodge City, KS & 22 & 17.9 & 14.5 & 11.9 & $8.8^{*}$ \\
\hline Flint, MI & 31 & 10.4 & 16.7 & 14.8 & 8.6 \\
\hline Great Falls, MT & 62 & 23.7 & 17.2 & 15.7 & 8.8 \\
\hline Green Bay, WI & 66 & 23.0 & 15.4 & 14.6 & 6.4 \\
\hline Greensboro, NC & 11 & 21.1 & 10.9 & 8.7 & $6.4 *$ \\
\hline Huntington, WV & 52 & 24.0 & 13.6 & 12.4 & 5.0 \\
\hline Huron, SD & 54 & 24.4 & 16.6 & 14.0 & 6.9 \\
\hline International Falls, MN & 78 & 20.9 & 18.7 & 18.4 & 6.6 \\
\hline Lander, WY & 124 & 26.7 & 16.9 & 16.5 & 7.5 \\
\hline Nashville, TN & 10 & 19.0 & 12.1 & 11.3 & $4.0^{*}$ \\
\hline North Omaha, NE & 26 & 17.5 & 16.6 & 16.7 & $8.2^{*}$ \\
\hline North Platte, NE & 33 & 18.7 & 13.4 & 12.6 & 7.4 \\
\hline Peoria, IL & 47 & 27.7 & 16.6 & 15.7 & 7.3 \\
\hline Pittsburgh, PA & 48 & 19.0 & 13.9 & 11.7 & 6.3 \\
\hline Portland, ME & 94 & 33.9 & 12.7 & 11.3 & 6.2 \\
\hline Rapid City, SD & 40 & 15.3 & 14.2 & 13.1 & 5.9 \\
\hline Saint Cloud, MN & 6 & 1.8 & 14.3 & 14.4 & $2.2 *$ \\
\hline Salt Lake City, UT & 56 & 17.4 & 14.8 & 12.4 & 7.9 \\
\hline Sault Ste. Marie, MI & 195 & 27.2 & 17.0 & 15.7 & 6.8 \\
\hline Topeka, KS & 24 & 21.9 & 19.6 & 20.8 & $6.2 *$ \\
\hline Washington/Dulles International Airport, VA & 22 & 18.1 & 14.3 & 12.3 & $8.0^{*}$ \\
\hline
\end{tabular}

accumulation of snow on the ground. Users may then wish to apply their own correction for wind speed and gauge type.

Since the snow density is a function of the habit and size of the ice crystals, which in turn is a function of the vertical temperature and moisture structure of the atmosphere, we desire collocated atmospheric soundings at the time of the snowfall. Sounding data were used from the NCDC/Forecast Systems Laboratory North American radiosonde dataset [Schwartz and Govett (1992); information online at http://raob.fsl.noaa.gov/ Raob_Software.html]. Only events with surface winds from the radiosonde data less than or equal to $9 \mathrm{~m} \mathrm{~s}^{-1}$ were used to avoid events where substantial blowing and drifting snow may have occurred. Since stations were at different elevations, the height above sea level reported in the radiosonde data was converted to a nondimensional height above ground. As in Roebber et al. (2003, their Table 1), this nondimensionalization was accomplished by using $\sigma$ coordinates, where $\sigma=p / p_{\text {surf }}$, with $p$ being pressure and $p_{\text {surf }}$ the surface pressure. The combination of the surface and upper-air criteria produced a total of 1650 twelve-hour snowfall events, hereafter called the dataset.
Roebber et al. (2003, their Table 2) used principal component analysis to extract a set of six factors from the sounding data. These six factors were low-midlevel temperature (F1), low-midlevel relative humidity (F2), mid-upper-level temperature (F3), upper-level relative humidity (F4), midlevel relative humidity (F5), and external compaction caused by surface wind and precipitation amount (F6). A seventh index based on the month represented solar radiation or ground temperature.

\section{Geographic distribution}

The mean snow ratio for the 1650-member dataset is 15.6, which is higher than the median of 14.1, indicating skewness toward higher snow ratios (Fig. 1). Therefore, as discussed in Roebber et al. (2003), forecasting a constant 10:1 snow ratio for snowfall events is not likely to be ideal for all situations. The mode of the dataset, however, is $10: 1$, with $14 \%$ of the events having snow ratios between 9:1 and 11:1 (Fig. 1), indicating some weak validity for the 10:1 rule. The shape of this curve and its skewness toward high ratios are consistent with previously published studies (see Roebber et al. 2003, 


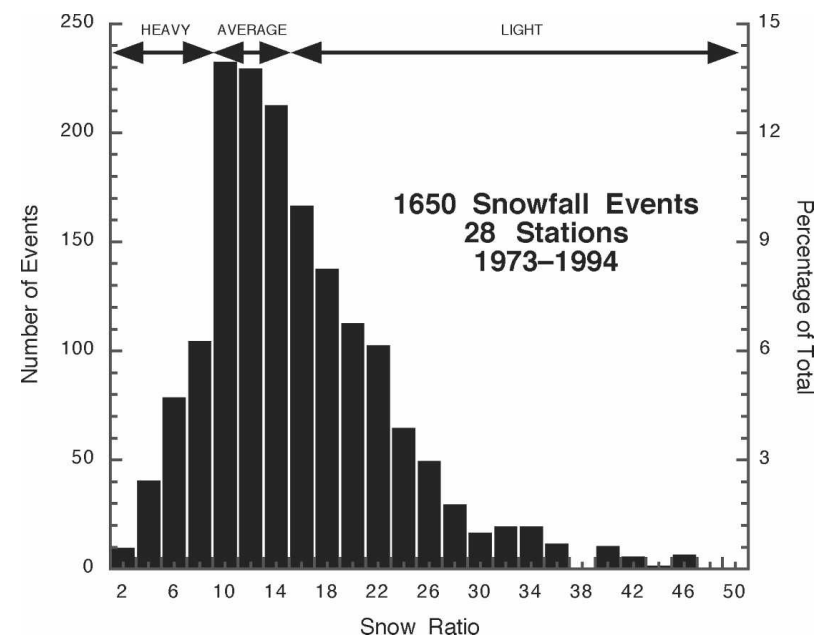

FIG. 1. Distribution of snow ratios for all 1650 12-h snowfall events. The vertical axis shows the number of events on the left and the percentage of total events on the right of the graph. The categories of light, average, and heavy are defined in the text. These data have not been corrected for wind speed or other gauge biases.

p. 268). These results are higher than the other comprehensive climatology of snow ratios for the United States by Baxter et al. (2005), who found a mean (median) of 13.5 (12.1). We suspect the difference is because our data is based on 6-h snowfall amounts and their data is based on the 24-h cooperative observer data, where greater compaction and lower snow ratios would be expected.

The snow ratios are classified into three classes: average (between 9:1 and 15:1), light ( $>15: 1$ ), and heavy $(<9: 1)$. The dataset consists of $14 \%$ heavy, $41 \%$ average, and $45 \%$ light. To better discriminate among the different conditions determining snow ratio, we first explore the geographic variability of the dataset.

Figure 2 shows a map of the distributions of snow ratio for all 28 stations, and Table 1 presents a list of statistical properties of the snow ratio at each station. The distributions show substantial regional variability. Because the frequency of snow is greater farther north, locations in the north have larger numbers of events, thus producing more robust snow-ratio distributions. Stations in the north also tend to have a greater frequency of higher snow ratios (Fig. 2). For example, the station with the highest mean (median) (with at least 30 events) is International Falls, Minnesota (INL), with 18.7 (18.4) (Table 1). In contrast, stations with the lowest mean (median) are Greensboro, North Carolina, and Nashville, Tennessee, with 10.9 (8.7) and 12.1 (11.3), respectively (Table 1). Comparing the seven factors between these stations indicates that the largest differences are primarily manifest by the warmer tro- pospheric temperatures (F1 and F3) at the southern stations (not shown).

Even stations in close proximity can have quite different distributions of snow ratio (e.g., Super and Holroyd 1997; Judson and Doesken 2000). For example, the distribution at Buffalo, New York (BUF) is skewed toward higher snow ratios compared to Albany, New York (ALB), only $400 \mathrm{~km}$ away (Fig. 2). The histograms of the tropospheric temperatures (F1 and F3) show the greatest differences between BUF and ALB (not shown), indicating that BUF tends to be colder throughout the troposphere during snow events than ALB. Similarly, the distance between Denver, Colorado (DEN), and Lander, Wyoming (LND), is only 475 $\mathrm{km}$, but Lander has a higher mean snow ratio and a significantly higher median snow ratio than Denver. The largest difference between these two cities occurs with the compaction factor (F6), with Denver having a much higher compaction factor (not shown). Examining the distributions of the two components of the compaction factor individually (liquid equivalent and wind speed) shows that the mean and median wind speeds were about $50 \%$ greater at DEN than at LND, whereas the liquid equivalents had nearly identical statistical distributions (not shown).

The geographical distribution of snow ratio in Fig. 2 is comparable to that of Baxter et al. (2005), who examined 24-h precipitation and snow amounts for 7760 National Weather Service cooperative observing sites for 1971-2000. The larger number of stations in their study enabled them to resolve mesoscale variations in the climatology of snow ratio. Since their study used 24-h snowfall compared to our study that used two 6-h snowfall measurements, some discrepancy may exist, with our events having higher snow ratios due to the reduced compaction effect (e.g., Roebber et al. 2003), especially for large snowfalls.

The factors that control the distribution of snow ratio depend on the types of weather patterns (i.e., the climate) experienced at each station. As discussed in Roebber et al. (2003), the vertical temperature and humidity profile at the time the snow is falling, the weight of the snow, the surface wind, and solar radiation (month) had the greatest effect on snow ratio. To explore these factors in more depth, we next investigate the statistical properties of the dataset in terms of these parameters.

\section{Influence of temperature on snow ratio}

Temperature plays an important role in determining snow density. One way in which this occurs is through the habit of the ice crystals, which is a strong function of 


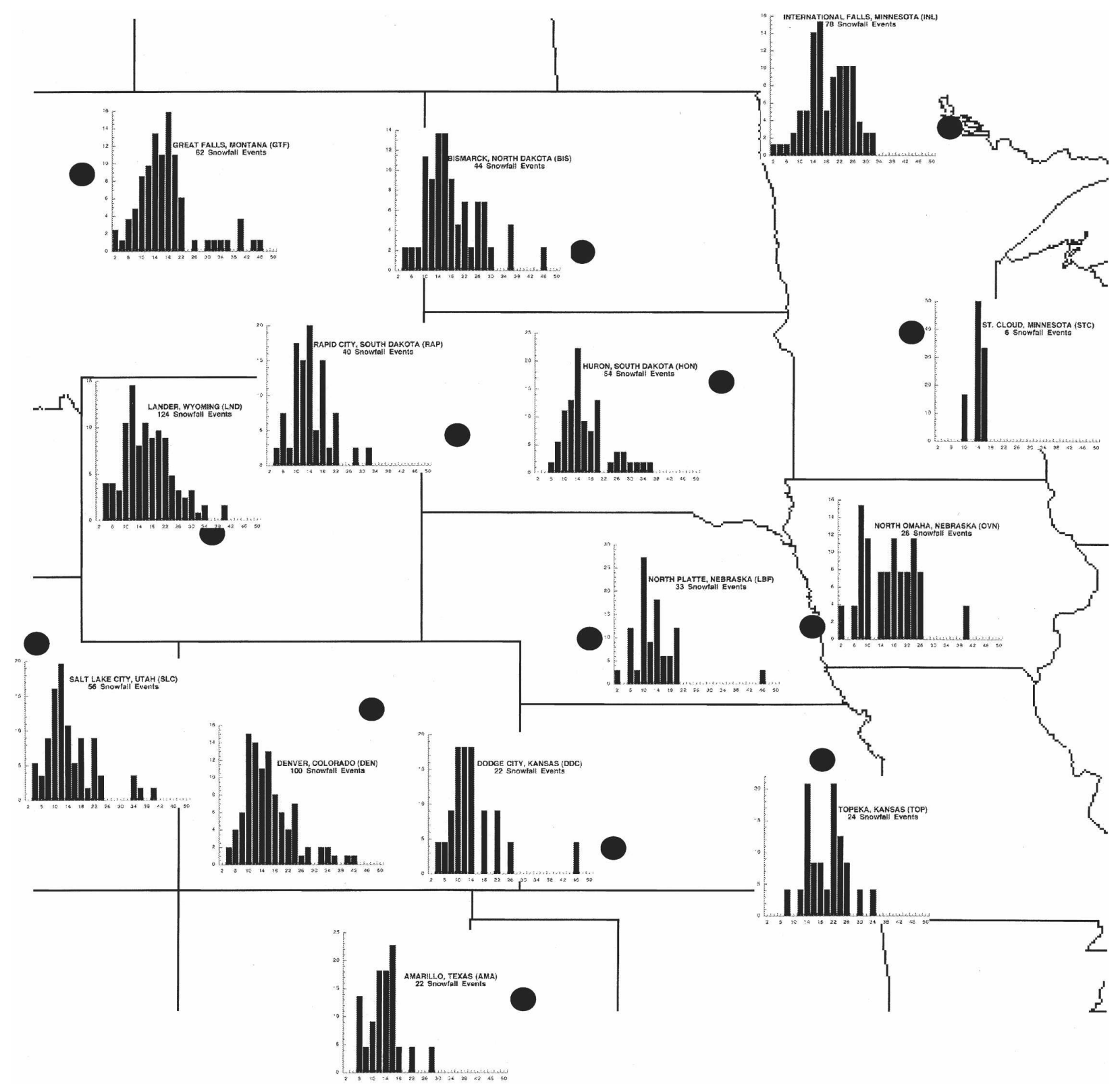

FIG. 2. Distributions of snow ratios for each of the 28 stations and their locations: (a) the western and (b) the eastern United States. Abscissa of the graphs of the individual stations are identical to that in Fig. 1. The ordinates are given in terms of percentage of events and have varying ranges among the stations. These data have not been corrected for wind speed or other gauge biases.

the temperature at which they grow (e.g., Magono and Lee 1966; Ryan et al. 1976; Fukuta and Takahashi 1999). Dendrites, which grow between $-10^{\circ}$ and $-20^{\circ} \mathrm{C}$, have large interstitial air spaces in the crystal structure, thereby yielding a low snow density (e.g., Figs. 11 and 12 in Fukuta and Takahashi 1999; Table 2 in Rasmussen et al. 1999). On the other hand, needles, which grow at temperatures between $-4^{\circ}$ to $-10^{\circ} \mathrm{C}$, are comparatively more dense (e.g., Figs. 11 and 12 in
Fukuta and Takahashi 1999; Table 2 in Rasmussen et al. 1999).

Another way that temperature may affect the density of snowfall is through the aggregation of airborne snow crystals. Aggregation is more effective at temperatures near $0^{\circ} \mathrm{C}$, as well as at the temperature of dendritic growth (around $-15^{\circ} \mathrm{C}$ ) (Hobbs et al. 1974, their Figs. 8 and 9a). Heymsfield (1986) also argues for the importance of aggregation at temperatures of $-25^{\circ}$ to $-36^{\circ} \mathrm{C}$ 


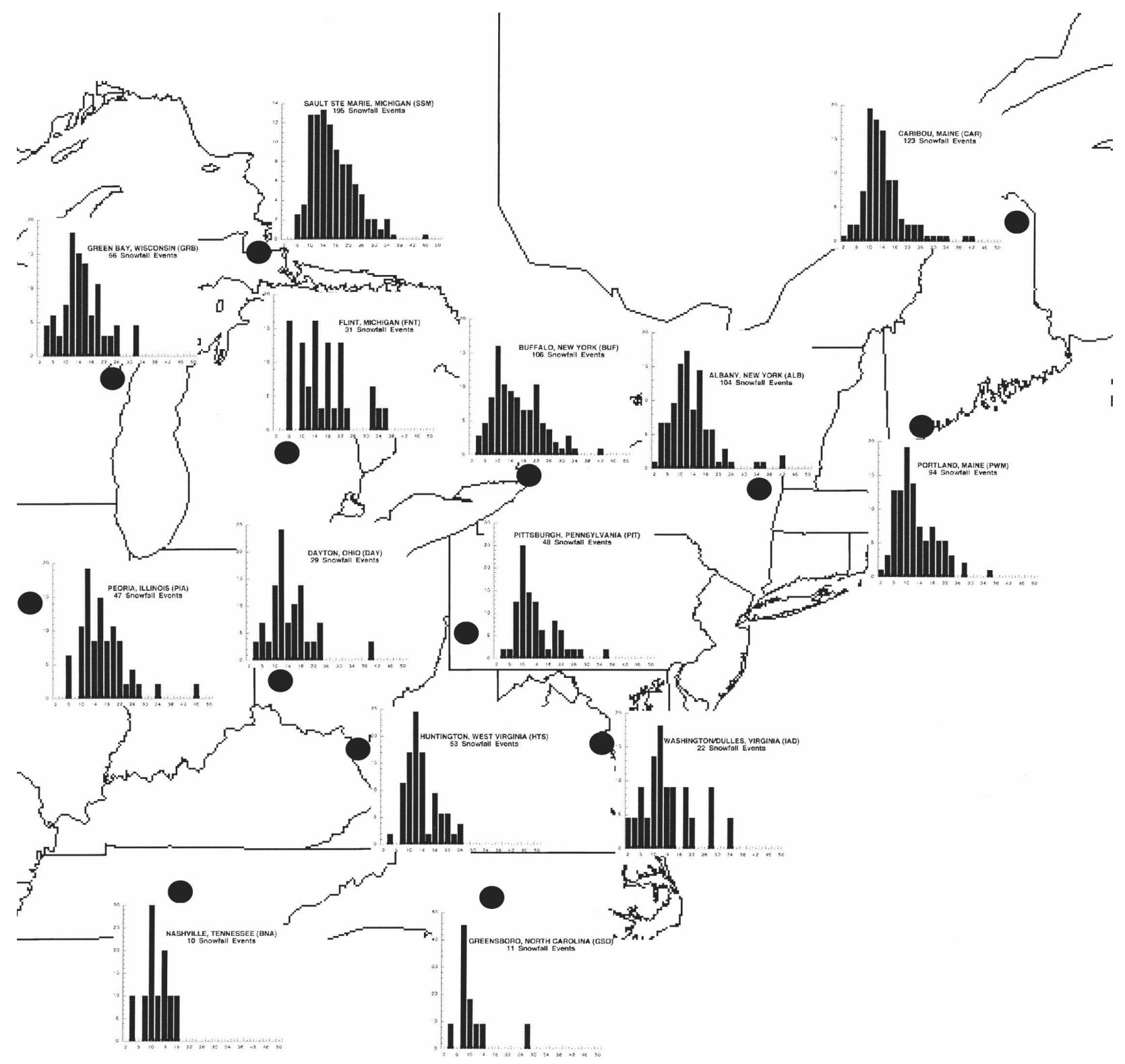

FIG. 2. (Continued)

in cumulonimbus anvils. Whether the degree of aggregation has any effect on the ultimate density of snowfall is unknown, because the action of snowflakes falling on the ground or snow surface, and subsequent accumulation, may involve more forceful collisions than those that occur during free fall. We are aware of no studies that have addressed this issue.

To explore the effect of low-level temperature on snow ratio, the 1650 snowfall events were divided into quintiles based on the low-level temperature factor (F1) derived in Roebber et al. (2003). (Low-level temperature was defined by the average of the temperature from $\sigma=1.0$ to $\sigma=0.8$, which was equivalent to the surface to about $850 \mathrm{mb}$.) Roebber et al. (2003) showed that the correlation between F1 and surface temperature was 0.94 , suggesting that surface temperature was a good proxy for F1. The cumulative distribution frequency plots (CDFs) of the temperature quintiles (Fig. 3 ) vary monotonically across snow ratios, in agreement with Roebber et al. (2003, Fig. 6b). The F1 quintile ranges and their corresponding temperatures are found in Table 2. The highest snow ratios were associated with the lowest $20 \%$ of low-level temperatures (F1 < -0.774 or low-level temperatures less than approximately $-10.1^{\circ} \mathrm{C}$ ), and the lowest snow ratios associated with the highest $20 \%$ of low-level temperatures (F1 > 


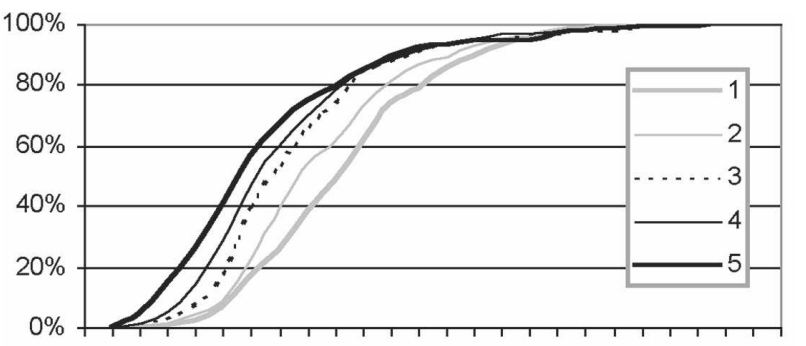

o 2468101214161820222426283032343638404244464850

\section{Snow Ratio}

FIG. 3. Cumulative distribution of snow ratios for low-level (below $850 \mathrm{mb}$ ) temperature quintiles. For corresponding F1 and temperature ranges to quintiles, see Table 2 . These data have not been corrected for wind speed or other gauge biases.

0.812 or low-level temperatures greater than approximately $-2.7^{\circ} \mathrm{C}$ ) (Fig. 3). The medians range from 18.2 for the lowest $20 \%$ of low-level temperatures to 11.4 for the highest $20 \%$ of low-level temperatures. More specifically, these CDFs could be used by forecasters to predict what snow ratios are not likely to occur. For example, low-level temperatures in the highest quintile rarely yield snow ratios over $25: 1$ (only about $5 \%$ of events exceed 25:1), whereas low-level temperatures in the lowest quintile yield snow ratios less than 10:1 less than $5 \%$ of the time. Thus, even though the snow ratio depends on factors other than temperature, potentially useful forecasting insight might be derived from the data presented in this manner.

\section{Influence of liquid equivalent on snow ratio}

In Roebber et al. (2003, Fig. 6d), both liquid equivalent and wind speed were combined into a surface compaction factor. Extracting the individual effects of these two terms was not performed. To explore the effects of each term independently, we first consider the liquid equivalent. Section 6 considers the effect of the wind speed independently.

One moisture-related parameter that discriminated among snow ratios well was the liquid equivalent of

TABLE 2. The F1 quintiles and temperature ranges for the dataset. The data have not been corrected for wind speed or other gauge biases.

\begin{tabular}{ccc}
\hline \hline Quintile & F1 range & Temperature range $\left({ }^{\circ} \mathrm{C}\right)$ \\
\hline 1 & 4.2 to -0.8 & -25.6 to -10.1 \\
2 & -0.8 to -0.09 & -10.1 to -6.9 \\
3 & -0.09 to 0.4 & -6.9 to -4.6 \\
4 & 0.4 to 0.8 & -4.6 to -2.7 \\
5 & 0.8 to 4.0 & -2.7 to 12.1 \\
\hline
\end{tabular}

snow. Physically, there are two possible reasons for this. First, snowfalls with high liquid equivalents may come from clouds with high cloud water content, implying a greater likelihood of riming or higher-density crystal habits. Second, the higher the liquid equivalent, the greater the weight of the snowpack, which would lead to greater compaction and smaller snow ratios. In contrast, snow ratios approaching 100:1 have been anecdotally associated with accumulations of a dusting to an inch. As with the other parameters, the dataset was divided into quintiles based on the liquid equivalent. As expected, the CDFs monotonically decrease with increasing liquid equivalent, with the lowest $20 \%$ of liquid equivalents yielding much larger snow ratios than the highest $20 \%$ of liquid equivalents (Fig. 4). More specifically, the medians differ from 9.4:1 for liquid equivalents greater than $11.2 \mathrm{~mm}$ (top $20 \%$ ) to $21.5: 1$ for liquid equivalents $2.8-4.1 \mathrm{~mm}$ (bottom 20\%). In fact, liquid equivalents $2.8-4.1 \mathrm{~mm}$ produced no ratios less than 14:1, and liquid equivalents greater than 11.2 mm produced less than $1.4 \%$ of events with snow ratios greater than 26:1. This dataset implies a negative correlation between liquid equivalent and snow ratios.

Because of the strong relationship between liquid equivalent and snow density, it is possible to create a potentially useful nomogram for forecasters. We compared the distributions of liquid equivalent to the 12-h snowfall for the 1650 cases. For ease of application in an operational forecasting environment, the five curves in Fig. 5 are not the same as the quintiles in Fig. 4, although they are close. The total percentage of the dataset encompassed by each curve is listed within the legend in Fig. 5. This nomogram can be used by forecasters to provide probabilistic guidance for 12-h snowfall for liquid equivalent less than $12.5 \mathrm{~mm}$ (0.5 in.). For example, a liquid equivalent of $2.8-5.0 \mathrm{~mm}(0.11-0.2$ in.) has produced 12-h snowfalls of $50-225 \mathrm{~mm}(2-9$ in.), although $50 \%$ of the events result in a snowfall of $75 \mathrm{~mm}$ (3 in.). Likewise, a good estimate of the 12-h snowfall can be determined for other liquid equivalent ranges. Eighty percent of the snowfalls with $5.0-7.5 \mathrm{~mm}$ (0.2-0.3 in.) of liquid equivalent will yield $75-150 \mathrm{~mm}$ (3-6 in.) of snowfall. Caution should be exercised in applying Fig. 5 for liquid equivalents over $12.5 \mathrm{~mm}(0.5$ in.) because of the wide distribution of 12-h snowfalls and inadequate sampling at very large snow accumulations. Of course, such situations are likely to produce the most socioeconomic impact, as well.

\section{Influence of surface wind speed on snow ratio}

Surface wind speed can affect the snow ratio. Surface winds exceeding approximately $9 \mathrm{~m} \mathrm{~s}^{-1}$ can move ice 


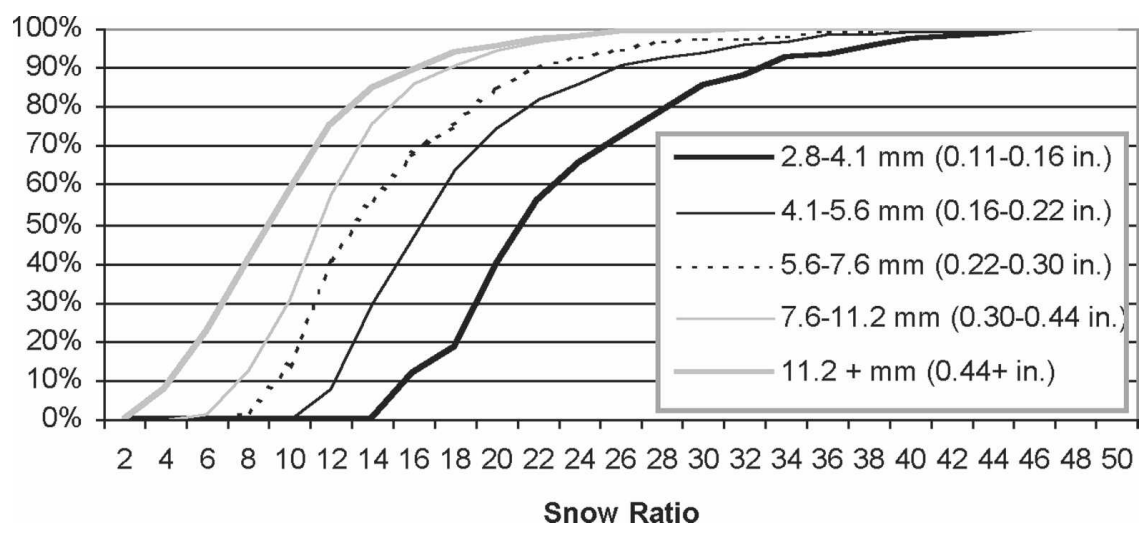

FIG. 4. Cumulative distribution of snow ratios for liquid equivalent quintiles. Value of 2.8-4.1 mm represents the lowest fifth of liquid equivalent values, and $11.2+\mathrm{mm}$ represents the highest fifth of liquid equivalent values. These data have not been corrected for wind speed or other gauge biases.

crystals at the surface, fracturing the crystal during saltation and increasing the snow density (e.g., Gray and Male 1981, 345-350). Therefore, only snow events occurring at wind speeds below $9 \mathrm{~m} \mathrm{~s}^{-1}$ were considered. Classifying the snow events by snow-ratio bin and plotting the fraction of events as a function of wind speed results in Fig. 6. Although the fraction of average snow ratios is constant with wind speed, the fraction of heavy snow ratios increases with wind speed from about $10 \%$ at low wind speeds to about $20 \%$ at $9 \mathrm{~m} \mathrm{~s}^{-1}$ (correlation coefficient of 0.572). In addition, the fraction of light snow ratios decreases with wind speed from about $53 \%$ at low wind speeds to $40 \%$ at $9 \mathrm{~m} \mathrm{~s}^{-1}$ (correlation coefficient of -0.507). These relationships are statistically significant at the $98 \%$ level. If considered in isolation, the wind speed plays a small, but significant, role in determining the snow ratio by shifting the distribution

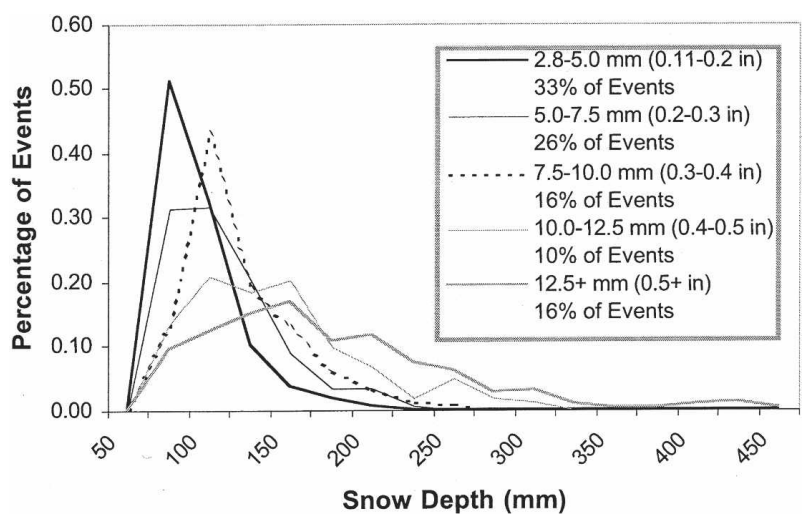

FIG. 5. Distribution of snowfalls for values of liquid equivalent. The vertical axis represents the fraction of events in each respective group. These data have not been corrected for wind speed or other gauge biases. of snow ratio toward lower values at higher wind speeds (Fig. 6). This minor role for wind speed may be due partly to the way Roebber et al. (2003) compiled their data, using 6-h observations to minimize effects of prolonged wind compaction on snow ratio. However, Roebber et al. (2003) also showed that wind speed can be quite important when combined with other parameters. In addition, accounting for the gauge undercatch (e.g., Goodison 1978; Yang et al. 1998) may also lead to a stronger relationship between snow density and wind speed.

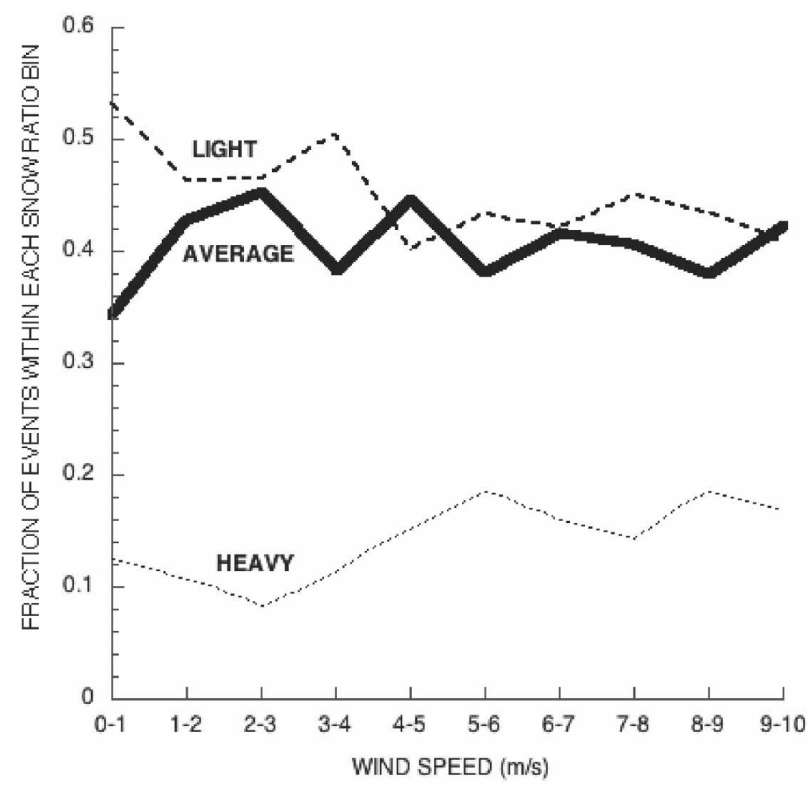

FIG. 6. Fraction of snow events within each snow-ratio bin (i.e., light, average, heavy) as a function of wind speed. These data have not been corrected for wind speed or other gauge biases. 


\section{Summary}

This paper attempts to provide forecasters with more information about snow ratios, following up on our earlier study (Roebber et al. 2003). First, a Web-based application for use in operational forecasting to predict 12-h snow ratios probabilistically using the neural network methodology of Roebber et al. (2003) is available. Second, the climatology of the snow ratios using the dataset previously constructed is explored with regard to geographic location, temperature, liquid equivalent, and wind speed. These results can be summarized in the following manner.

1) Snow ratio tends to increase as the low-level (surface to roughly $850 \mathrm{mb}$ ) temperature decreases.

- Mean low-level temperatures greater than $-2.7^{\circ} \mathrm{C}$ rarely (less than $5 \%$ of the time) produce snow ratios greater than 25:1.

- Mean low-level temperatures less than $-10.1^{\circ} \mathrm{C}$ rarely produce snow ratios less than 10:1.

2) Snow ratio tends to increase as the liquid equivalent decreases.

- Liquid equivalent amounts 2.8-4.1 mm (0.11-0.16 in.) rarely produce snow ratios less than 14:1.

- Liquid equivalent amounts greater than $11.2 \mathrm{~mm}$ (0.44 in.) rarely produce snow ratios greater than 26:1.

3) Increasing surface wind speed has a small, but significant, role in decreasing snow ratio.

In using the techniques described in this paper, forecasters must remember the following caveats implicit in this research. First, the Roebber et al. (2003) dataset may be unrepresentative for certain situations. For example, the dataset does not capture the extreme events; thus, the tails of the distributions may not be sampled adequately. Other examples where the dataset may be unrepresentative derive from the criteria we used for constructing the dataset. For example, this dataset cannot address 12-h snowfalls where the liquid equivalent values are less than $2.8 \mathrm{~mm}$ (0.11 in.), 12-h snow amounts are less than $50.8 \mathrm{~mm}$ (2.0 in.), and surface wind speeds are greater than $9 \mathrm{~m} \mathrm{~s}^{-1}$.

Second, the techniques described in this note were developed probabilistically. With many of these distributions skewed toward high snow ratios, the state of the science is not sufficiently advanced to ascertain absolute cutoffs. Thus, the term "rarely" implies probabilities less than $5 \%$ of the sampled population.

Third, these snowfall data have not been corrected for gauge bias, of which the largest source of error appears to be the type of gauge and wind screen available (e.g., Goodison 1978; Doesken and Judson 1997; Yang et al. 1998). Although regression equations exist for "correcting" these data for wind speed (e.g., Yang et al. 1998), we have chosen not to employ such corrections. As was noted by one anonymous reviewer, not correcting for gauge bias may have a potentially negative impact on the accuracy of our neural network in Roebber et al. (2003). In this situation, we prefer not to tamper with the original data by imposing an arbitrary and empirical correction for one of a number of possible biases in the precipitation data.

Fourth, the combination of effects (e.g., temperature, liquid equivalent, wind speed) is what makes prediction of the snow ratio difficult. Even though the artificial neural network approach was not perfect, the actual prediction in a specific case may be strongly modified by the conditions represented by the other effects (Roebber et al. 2003, p. 277). Thus, inherent limitations exist to any approach, including the guidance suggested in this paper.

Applying the generalizations described above derived from the statistical properties of the dataset constructed by Roebber et al. (2003) could help isolate many of the extreme occurrences of snow ratios, when the values are either large (greater than 20) or small (less than 10). Therefore, if these extreme values could be ascertained ahead of time, human forecasters can play an important role in minimizing the potential forecast busts due to application of a constant snow ratio to liquid equivalent (e.g., 10:1) from numerical weather prediction model output. If the numerical forecast models accurately represent the forecast scenario, then a Web-based application is available, as described in section 1.

Acknowledgments. Part of this paper resulted from a summer research course and a senior Capstone class taken by EW at the University of Oklahoma School of Meteorology, taught by Dr. Andy White. Steve Jessup, Mary Beth Riley, and three anonymous reviewers provided comments that improved earlier versions of this manuscript. Funding for Schultz was provided by NOAA/OAR/NSSL under NOAA-OU Cooperative Agreement NA17RJ1227.

\section{REFERENCES}

Baxter, M. A., C. E. Graves, and J. T. Moore, 2005: A climatology of snow-to-liquid ratio for the contiguous United States. Wea. Forecasting, 20, 729-744.

Currie, B. W., 1947: Water content of snow in cold climates. Bull. Amer. Meteor. Soc., 28, 150-151.

Doesken, N. J., and A. Judson, 1997: The Snow Booklet: A Guide to the Science, Climatology, and Measurement of Snow in the United States. Dept. of Atmospheric Science, Colorado State University, $86 \mathrm{pp}$. 
Fukuta, N., and T. Takahashi, 1999: The growth of atmospheric ice crystals: A summary of findings in vertical supercooled cloud tunnel studies. J. Atmos. Sci., 56, 1963-1979.

Goodison, B. E., 1978: Accuracy of Canadian snow gage measurements. J. Appl. Meteor., 17, 1542-1548.

Gray, D. M., and D. H. Male, 1981: Handbook of Snow: Principles, Processes, Management and Use. Pergammon Press, $776 \mathrm{pp}$.

Groisman, P. Ya., and D. R. Easterling, 1994: Variability and trends of total precipitation and snowfall over the United States and Canada. J. Climate, 7, 184-205.

Heymsfield, A. J., 1986: Ice particle evolution in the anvil of a severe thunderstorm during CCOPE. J. Atmos. Sci., 43, 24632478.

Hobbs, P. V., S. Chang, and J. D. Locatelli, 1974: The dimensions and aggregation of ice crystals in natural clouds. J. Geophys. Res., 79, 2199-2206.

Judson, A., and N. Doesken, 2000: Density of freshly fallen snow in the central Rocky Mountains. Bull. Amer. Meteor. Soc., 81, 1577-1587.

LaChapelle, E. R., 1962: The density distribution of new snow. Project F, Progress Rep. 2, Alta Avalanche Study Center, Wasatch National Forest, USDA Forest Service, Salt Lake City, UT, 13 pp.

Magono, C., and C. W. Lee, 1966: Meteorological classification of natural snow crystals. J. Fac. Sci., Hokkaido Univ., Ser. 7, II, 321-335.

Power, B. A., P. W. Summers, and J. d'Avignon, 1964: Snow crys- tal forms and riming effects as related to snowfall density and general storm conditions. J. Atmos. Sci., 21, 300-305.

Rasmussen, R. M., J. Vivekanandan, J. Cole, B. Myers, and C. Masters, 1999: The estimation of snowfall rate using visibility. J. Appl. Meteor., 18, 1542-1563.

Roebber, P. J., S. L. Bruening, D. M. Schultz, and J. V. Cortinas Jr., 2003: Improving snowfall forecasting by diagnosing snow density. Wea. Forecasting, 18, 264-287.

Ryan, B. F., E. R. Wishart, and D. E. Shaw, 1976: The growth rates and densities of ice crystals between $-3^{\circ} \mathrm{C}$ and $-21^{\circ} \mathrm{C}$. J. Atmos. Sci., 33, 842-850.

Schwartz, B. E., and M. Govett, 1992: A hydrostatically consistent North American radiosonde data base at the Forecast Systems Laboratory, 1946-present. NOAA Tech. Memo. ERL FSL-4, 81 pp. [Available from NOAA/FSL, 325 Broadway, Boulder, CO 80303.]

Super, A. B., and E. W. Holroyd III, 1997: Snow accumulation algorithm for the WSR-88D radar: Second annual report. Bureau of Reclamation Tech. Rep. R-97-05, U.S. Dept. of Interior, Denver, CO, 77 pp. [Available from National Technical Information Service, 5285 Port Royal Rd., Springfield, VA 22161.]

Yang, D., B. E. Goodison, J. R. Metcalfe, V. S. Golubev, R. Bates, T. Pangburn, and C. L. Hanson, 1998: Accuracy of NWS 8" standard nonrecording precipitation gauge: Results and application of WMO intercomparison. J. Atmos. Oceanic Technol., 15, 54-68. 